\title{
Un Krader desconocido
}

\author{
Andrés Fábregas
}

LAWRENCE KRADER, 2003

\section{Mito e ideología}

INAH, México, 374 pp.

T awrence Krader llegó a México en

1 1977, invitado por Ángel Palerm, su amigo y colega, para que sostuviera una serie de conferencias en el CISINAH, actual CIESAS, situado en la Casa Chata de Tlalpan, justo en donde hoy está la biblioteca que lleva el nombre de Palerm. Era un momento en que las discusiones entre los científicos sociales de México y los intelectuales en general, no escapaban al contexto de la Guerra Fría. En las izquierdas mismas privaba una intensa y no siempre cordial polémica acerca de la "interpretación correcta” de los textos marxistas y de allí, a cuál debería ser la posición política adecuada.
En particular, en los círculos intelectuales mexicanos, se discutía el caso del "modo asiático de producción" y de las teorías propuestas por Kart Wittfogel respecto a la llamada "sociedad hidráulica" (véase Kart W. Wittfogel, Oriental Despotism, Yale, Yale University Press, 1956). Esta última discusión alcanzó en México y Francia tintes particulares. La bibliografía alrededor del tema es abundante en ambos países. La propuesta más polémica de Wittfogel es la de que "Marx y Engels habían pecado contra la ciencia" porque "ocultaron" sus descubrimientos acerca del modo asiático de producción, debido a que el socia-

ANDRÉS FÁBREGAS: Universidad de Guadalajara.

Desacatos, núm. 13, invierno 2003, pp. 192-199.

lismo era una "restauración" del mismo. Palerm había situado la discusión del modo asiático en el contexto de la distinción entre el "evolucionismo unilineal" y el "evolucionismo multilineal”. Sólo los dogmáticos dudaban de que Marx mismo había propuesto el modo asiático de producción como una época en la formación económica de la sociedad. El "marxismo cerrado" sólo aceptaba como "modos de producción válidos" al esclavista, feudal, capitalista y socialista, situados en una perspectiva evolutiva unilineal. Además, se decía que Wittfogel estaba del lado "imperialista" en el contexto de la Guerra Fría y ello, para muchos, lo descalificaba como investigador y científico. En medio de este ambiente intelectual llegó Krader a México.

Poco se conocía en México de la obra de Krader cuando éste arribó al país. De hecho, en castellano sólo existía publicada la traducción de su artículo "Marx as Ethnologist" (véase Lawrence Krader, "Marx como etnólogo", Nueva Antropología, año I, núm. 2, México, octubre de 1975, pp. 3-23). 
Los discípulos de Palerm sabíamos un poco más de él por las conversaciones de café que solíamos sostener en la Universidad Iberoamericana y en la propia Casa Chata. Krader fue un estudioso de los pueblos de Asia y de la obra de Marx. Su erudición en ambos campos lo facultó a sostener una posición diferente a la de Wittfogel, a la que calificaba de resultado de la Guerra Fría. Una influencia marxista importante sobre Krader fue Karl Korsh, con quien discutió el contenido de los Cuadernos de notas etnológicas de Marx en los años de 1947 a 1953. Esta discusión con Korsh fue muy importante especialmente si se tiene en cuenta que había marxistas por un lado y antropólogos por otro, que negaban que Marx hubiese tenido interés alguno en las sociedades primitivas o en los problemas planteados por la antropología. Los Cuadernos de notas etnológicas desmienten esa opinión, mostrándonos a un Marx no sólo interesado en la antropología sino estudioso de ella. Con estos antecedentes, la presencia de Krader se acogió con interés en México y sus conferencias estuvieron concurridas en toda ocasión. Además del artículo "Marx as Ethnologist", Krader, para el año de 1977, había publicado The Ethnological Notebooks of Karl Marx (The Netherlands: Van Gourcum, 1972), obra cuya traducción castellana fue publicada por la editorial Siglo XXI en 1988. Así mismo, Dialectic of Civil Society (The Netherlands: Van Gourcum, 1976) y The Asiatic Mode of Production (The Netherlands: Van Gourcum, 1975). Como un resultado de su trabajo en Asia, Krader había publicado Social
Organization of the Mongol-Turkik Pastoral Nomadas (The Hague, Mouton, 1963). Antes, en 1968, Krader publicó un texto introductorio titulado The Formation of the State (Englewood Clifs, New Jersey, Prentice Hall, 1968). Dos años después de su estancia en México, Lawrence Krader publicaría su monumental A Treatise of Social Labor (The Netherlands, Van Gourcum, 1979), obra que discutió en el CIS-INAH y en conversaciones, mientras la escribía.

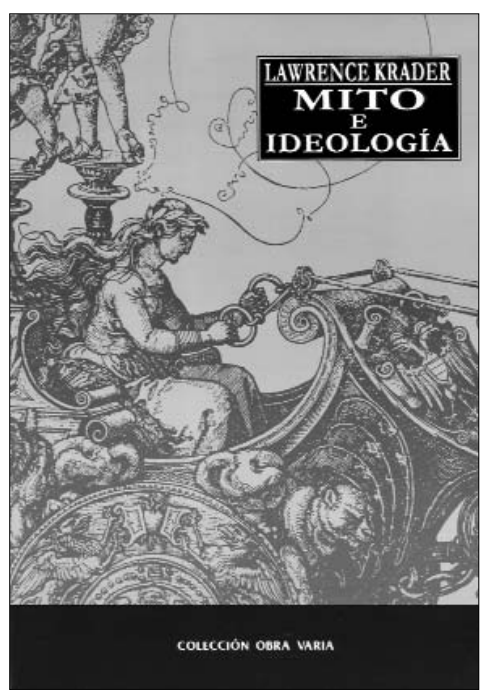

Tanto en sus conferencias como en sus cursos, Krader se mostró preocupado por discernir el proceso productivo y su influencia en la sociedad. En sus obras publicadas, el tema central de Krader es la dialéctica de la historia analizada a través de la formación de épocas económicas. Por esta razón, un libro como Mito e ideología viene a ser una excepción que confirma el conjunto de la obra kraderiana. En efecto, en este libro Krader escribe sobre la cultura, analizando el papel del mito y la ideología en la historia humana.

Mito e ideología abre con una semblanza del autor escrita por una de sus discípulas y traductora del texto, Mayan Cervantes. Continúa con una presentación que escribe Alberto Cue. Enseguida el lector se encuentra con un preámbulo para pasar después a una introducción. Ambos textos están escritos por el propio Krader. A continuación, el libro se divide en tres secciones tituladas, "De la Antigüedad al siglo XX", "La teoría del mito" y "Forma y sustancia del mito". Cada sección contiene una serie de subtítulos de acuerdo con los diversos temas que Krader va desarrollando. La parte final de la obra está compuesta por las "Notas complementarias" debidas a Alberto Cue, la "Bibliografía en español de las obras citadas" y el "Índice onomástico". En total, 374 páginas, sin ilustraciones. La semblanza de Lawrence Krader lo sitúa en México y enfatiza la importancia de su presencia en nuestro medio. Mayan Cervantes conoció a Krader de cerca, trabajó con él y finalmente es a ella a quien le entregó el manuscrito de Mito e ideología con el encargo de que lo tradujera. La semblanza de Mayan cumple su propósito de introducir al lector en la perspectiva kraderiana y su traducción del texto honra la memoria de quien fuera su maestro.

Alberto Cue escribe una presentación que sitúa a Krader dentro de los estudiosos del mito, advirtiendo, con certeza, que ése no era el campo de especialización del autor. Este texto es una guía para leer el libro de Krader 
teniendo, además, la virtud de ser breve y de enfatizar lo que se debe.

En el "Preámbulo", Krader explica los propósitos que lo animaron a estudiar el mito advirtiendo que propondrá una teoría del mismo partiendo de un nuevo punto de vista. Plantea siete oposiciones desde las que debe estudiarse el mito, a saber: el mito en el tiempo y en el espacio, como verdad y como error, sagrado y secular, como expresión racional e irracional, en el pensamiento y en el sentimiento (o los elementos cognoscitivos y afectivos del mito) y, finalmente, el mito y la ideología: el mito en acción en las esferas política, económica y religiosa de la vida social.

En la sección "De la Antigüedad al siglo XX”, Krader comienza con el análisis de Platón y de Aristóteles. Tam-
Pasa a examinar el mito desde el Renacimiento hasta la Ilustración, empezando con Samuel Bochart (1646) y Marius de Assigni (1671) para seguir con Athanasius Kircher (1652), Antonius van Dale (1724) y Bernard Fontenelle (1724). Alexander Pope y Juan Jacobo Rousseau representan las actitudes contrapuestas en torno al "salvaje”. Krader escribe: "En el siglo XVIII, pues, había un conflicto profundo entre quienes celebraban la pureza de la vida de los salvajes y aquellos que les atribuían un estado de ánimo ignorante e irracional, que se expresaba en sus mitos" (p. 57). Krader se detiene en el siglo XVIII discutiendo con detalle a personajes como Banier, Thomas Blakcwell, Giambattista Vico, Voltaire, Adam Ferguson, Herder. De aquí, Krader se introduce directamente al siglo XX (pp. 61 y ss.) afirmando que es en ese siglo cuando se inició el estudio objetivo, empírico y crítico del mito. Autores como Schlegel, Heyne, Voss, Creuzer, Chompre, De Maistre, son comentados por Krader en relación al tratamiento del mito. Krader concede un espacio particular a Hegel y los hegelianos (pp. 65 y ss.). Esta parte de la discusión de Krader interesa particularmente a quienes se afanan por el estudio del simbolismo desde posiciones hermenéuticas. Krader alude a la distinción entre los hegelianos de izquierda y los hegelianos de derecha, alución que aparece antes en su "Marx as Ethologist" (1973). Los hegelianos de izquierda más distinguidos fueron Karl Marx, Federico Engels, Bruno Bauer, Moisés Hess, Arnold Ruge, Ludwig Feuberbach y Max Stirner. Entre los hegelianos que estudiaron el mito, Krader incluye a Bauer, Schelling, Renan, Arthur Shopenhauer, Hans Vaihinger y Max Scheler.

El subtítulo "Los estudiosos modernos del mito: los fundadores", se inicia con una discusión que abarca desde Bachofen hasta Frazer, pasando por autores como Afanasiev, Moriz Carriere, Müller, E. B. Tylor, Robertson Smith, Daniel Brinton, Adolf Bastian. En palabras de Krader: "Frazer es el precursor del estudio científico del mito" (p. 77). De paso, en esta sección, Krader advierte que la mitología es, precisamente, el análisis científico de los mitos.

Al abordar la obra de Émile Durkheim (p. 79), Krader resalta el hecho de que fue el sociólogo francés quien vinculó la mitología con el estudio de la sociedad. Esta parte del libro no sólo expone los planteamientos de Durkheim acerca del mito, sino que establece un diálogo entre autores como Davy, Baldwin Spencer, F. J. Gillen, Lucien Lévi-Bruhl, Henry Bergson, J. E. Harrison, F. M. Cornford, Herman Usener, Wilhem Nestle, Bruno Snell, J.-P. Vernanti. Una de las conclusiones que obtiene Krader de esta múltiple conversación es que el realismo social de Durkheim tuvo sus raíces en sus seguidores mismos.

"El mito como mito de los otros: el mito de Gilgamesh y el mito bíblico" (p. 87), es un subtítulo en el que Krader expone en resumen el poema de Gilgamesh, haciendo notar que, contrario a otras opiniones, no tiene relación alguna con el Antiguo Testamento. Más bien, Krader relaciona la discusión del poema con el surgimiento del evolucionismo. En efecto, una parte del poema de Gilgamesh es un mito etiológico. Bruno Snell pensó que el mito era parte de la evolución unilineal de la mentalidad humana en una dirección que culmina con la racionalidad. Alrededor de este planteamiento, Krader comenta a Frazer, Guthrie y Dodds.

Para otros autores, el mito es un intento de periodizar la historia (tema que Krader trata extensamente en relación con Marx en su The Asiatic Mode of Production). Algunos de estos autores son Henry Bergson, R. G. Collinwood, W. Nestle, Lucien LéviBruhl y Marcel Mauss. Krader discute la idea de algunos de que "la historia como un proceso va de lo irracional y misterioso a lo racional e ilustrativo" (p. 90). Collingwood es precisamente uno de los que así piensan. Krader no 
deja pasar la oportunidad para advertir la creación de un mito de la historia, enraizado en aquellos autores. Escribe: "Quienes han escrito sobre la periodificación de la historia, colocando su propio trabajo en ella, dentro de un período considerado como el último, han creado un mito de la historia, en el sentido de cuento o trama. El mito en este caso no es el mito del otro, sino el de uno mismo, que es el otro, por lo que el mito es el del yo" (p. 93). Es decir, existe una concepción etnocéntrica del mito que se manifiesta en la forma en que algunos escriben la historia.

Sigue el subtítulo "Algo sobre el mito de Gilgamesh", bajo el cual Krader discute la obra de M. K. Munitz, Space, Time and Creation (Dover, 1981), que es un planteamiento del desarrollo que siguió la cosmología del mito hacia la ciencia (p. 96).

En el siguiente subtítulo, "La fuerza del mito en nuestro tiempo: Sorel, $\mathrm{Pa}$ reto, Weber y Mannheim" (p. 97), el autor trata el hecho de que al despuntar el siglo XX, los enfoques $\mathrm{y}$ planteamientos sobre el mito continuaron, pero ignorándose el uno al otro. Sorel escribió que el mito "era un instrumento" para influir en el presente. Esta opinión se aproxima al concepto de ideología y, de hecho, Krader regresa a este autor al final de su libro, como también lo hace notar Alberto Cue en su "Nota complementaria núm. 31" (p. 321). Pareto pensó como Sorel, sin separar el mito de la historia, pero reconociéndolo en el presente. En verdad, Sorel y Pareto están cercanos a las ideologías políticas en sus planteamientos del mito (p. 99).
Max Weber vio en el mito un proceso irracional que es superado a lo largo de la historia. El mito sugiere la mentalidad que subyace al contexto simbólico conceptual. Karl Mannheim (que leyó a Sorel, Pareto, Marx y Weber) afirmó que los mitos son ficciones. Es alrededor de esta problemática que Krader propone la discusión de los clásicos mencionados, comparándolos entre ellos. Es una de las secciones mejor logradas del libro. Krader descifra cómo los clásicos aplicaron la categoría de mito al análisis de los problemas sociales de su tiempo, a la ideología de las clases sociales y, en general, a la composición de la sociedad y sus conflictos.

En el subtítulo "El mito de otro tiempo y de otro espacio: la importancia de Cassirer", Krader discute a este filósofo kantiano, muy poco leído por los antropólogos mexicanos. Para introducir a Cassirer, Krader comenta brevemente la obra de Martin Buber y de W. F. Otto. El planteamiento de Cassirer se basa en una concepción mítico-religiosa en donde la formación de ideas es el hecho central. Para la "antropología simbólica" es importante la obra de Ernest Cassirer debido al énfasis que puso en el planteamiento de que el símbolo es una forma de concepción y de expresión. Según Cassirer, mediante los símbolos, la humanidad pasa de la concepción prelógica al conocimiento objetivo. Krader vincula la obra de Cassirer con la de varios estudiosos del mito como Kira, Langer, Lévi-Bruhl, Jensen, Schelling, Winkler. El autor resalta la importancia del libro de Ernest Cassirer, El mito del Estado, como una contribución al conocimiento de los mitos sociales.

Krader continúa analizando la obra de Cassirer en el subtítulo "Sobre la unidad psíquica de la especie humana” (p. 113). Dado que Franz Boas planteó su concepto de cultura desde una posición kantiana, la obra de Cassirer es pertinente a los antropólogos. En el siguiente subtítulo, "Los mitos de los pueblos del Pacífico Norte: Boas, Bogoratz, Jochelson" (p. 114), Krader llama la atención sobre las coincidencias entre Wilhem Wundt y Boas, sobre todo, la distinción en la que ambos insistieron, entre los conceptos mitológicos abstractos y los que son particulares y concretos. Boas -lo saben los antropólogos - fue un gran recopilador de cuentos, mitos y leyendas, y en general, de la tradición oral de los pueblos de la costa oeste estadounidense, como los tsimshim, kwakiutl y esquimales. Krader comenta las dos versiones del mito tsimshim de Adiwal y Asihwil (que Lévi-Strauss ha usado con insistencia para ilustrar cómo procede el análisis estrucural). De Bogoratz, estudioso de los yukagir y koryak, vecinos de los chukchi, pueblos del noreste de Siberia, prisionero político de los zares (fue miembro del movimiento "la voluntad del pueblo"), Krader comenta su análisis del mito chukchi de la creación. Así mismo, complementa este análisis con el de otros mitos de la creación elaborados por los mismos chukchi. Enseguida, compara la obra de Bogoratz con la de Jochelson (p. 125), ambos etnólogos de este pueblo. Lo que logra Krader es una revisión más o menos extensa de los mitos que cuentan los 


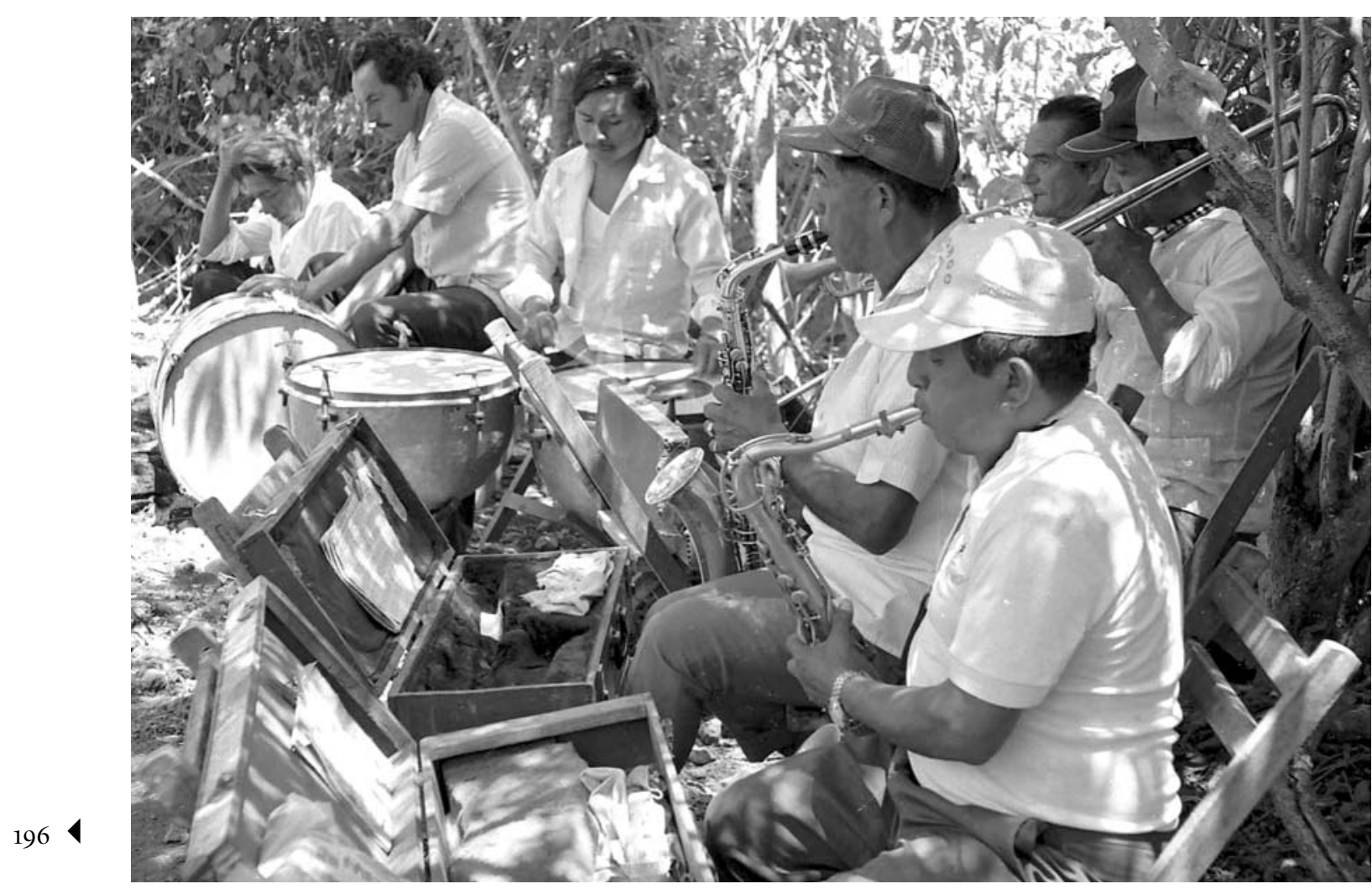

Jaraneros tocando en la fiesta del santo patrón, pueblo de Xocén / Christian Rasmussen.

chukchi, siguiendo las obras de Bogaratz y Jochelson, incluyendo un largo comentario sobre "el mito, el tiempo y el tiempo mítico" (pp. 130-139).

Al terminar la parte dedicada a los pueblos del noroeste de Siberia, Krader se pregunta, en otro subtítulo, “¿Qué es un mito verdadero?", respondiendo con el análisis de los mitos pawnee de la creación y del coyote. Se apoya en la obra de George Dorsey. Entre estos análisis y los de los mitos del embustero de los winnebago (p. 145), Krader intercala un comentario "sobre la relatividad de los estándares de la vida social y el mito" (p. 144) en donde escribe: "Si bien decimos que todos los mitos son igualmente válidos, no aprobamos la completa relatividad de los juicios que se expresan en los mitos. Un mito que aboga por el genocidio o el etnocidio, la explotación o la opresión de un pueblo por otro, es una expresión inhumana y luchamos contra quienes lo expresan" (p. 144). Este es el Lawrence Krader marxista, situado en la mejor tradición del pensamiento crítico. En congruencia, Krader no titubea en escribir: "El principio de una tolerancia absoluta fue sostenido por Voltaire, quien se supone le dijo a Helvecio: 'No estoy de acuerdo con lo que dices, pero defenderé hasta la muerte tu derecho a decirlo.' Este es un liberalismo peligroso; por ejemplo, hay defensores de nuestras libertades civiles que luchan porque los nazis y los racistas tengan libertad de reunirse; pero si con ello llegan al poder, nosotros perderemos ese derecho, junto con nuestras vidas. La tolerancia $o$ el liberalismo absolutos dejan de distinguir entre una regla de ley, que concierne a nuestras libertades civiles, y una regla que rige esa regla; esta es la distinción entre una regla de una lengua y una regla de un metalenguaje que rige esa lengua" (p. 144). Lo oportuno en estas palabras de Krader es obvio. 
El final de la sección titulada "De la Antigüedad al siglo XX”, es un largo análisis de la antropología dedicada al mito, con "los mitos del embustero" de los pawnee como ejemplo (pp. 145-151).

En la introducción a "La teoría del mito" (pp. 159-200) Krader agrupa en tres clases a las teorías del mito: las duraderas y constantes, las que caen después de aparecer, y las que van y vienen. En lo que continúa el consenso, desde la Antigüedad clásica hasta nuestros días, es en la opinión de que el mito es una expresión oral, anónima y popular. El análisis de Krader corresponde a quienes se han ocupado del mito en el siglo XX, agrupados en dos expresiones: los que consideran que los mitos originados en la tradición oral, si vienen de fuentes escritas, son por analogía los no escritos; $y$ quienes opinan que el mito secular es el importante, es decir, el que está en relación con nuestros intereses cotidianos e ideologías (p. 159). Los autores de ambos grupos escriben ignorándose mutuamente, además de que al interior de ellos existen serias divergencias de puntos de vista. A Krader no le interesa distinguir entre mito, fábula y leyenda, sino proponer una teoría general del mito.

Según Krader, "El mito es expresión de la poesía, de la sabiduría, de nuestros conocimientos y sentimientos más profundos" (p. 162). El desarrollo de este planteamiento es complejo. Krader regresa al examen de varios puntos de vista a través de varias secciones: "El mito y la esfera de lo posible" (p. 163), "El mito y los universales" (p. 164) y "La alegoría, el símbolo y la metáfora” (p. 172). La filosofía, la etnología, la lingüística, la crítica literaria y la crítica de arte, se entrelazan a través de la erudición de Krader. Al término de este ejercicio, Krader introduce al análisis etnológico propiamente dicho, examinando a los estructuralistas y en particular a Claude Lévi-Strauss y Edmund Leach. Sorprende leer en Krader la opinión de que las obras de Lévi-Strauss, "son admirables tanto por su maestría estilística como por su contenido" (p. 177), un reconocimiento que nunca obtuvo el maestro francés de parte de, por ejemplo, Ángel Palerm o Stanley

Diamond. La sorpresa ante este párrafo de Krader se produce porque no es desconocida su animadversión al estructuralismo en general y a la obra de Lévi-Strauss (antes de Mito e ideología, obviamente) en particular. Pero aquí estamos ante un Krader estudioso de la cultura que reconoce en LéviStrauss a un etnólogo fundacional. Así, escribe: "Su propio trabajo entre los indígenas bororó de Brasil, y sus lecturas detalladas de los informes de trabajo de campo de Franz Boas, constituyen las bases principales para su estudio del mito, a las que añadió las lecturas sobre los mitos de la Antigüedad clásica y los trabajos de literatura etnográfica” (p. 177).

Para revisar la obra de Lévi-Strauss, Krader adopta la noción de que la estructura es lo sincrónico opuesto a lo diacrónico. Por lo tanto, los estructuralistas abstraen el mito del tiempo y de la historia. En todo momento, al comentar a Lévi-Strauss, Krader muestra respeto por la obra de un colega, llegando a decir que "su idea de que el mito es no canónigo, no definitivo e independiente de un contexto lingüístico, es una conclusión poderosa e importante, apoyada en otros campos aparte del estructuralista” (p. 181).

El Krader simpatizante de LéviStrauss, incluso entusiasmado con el estructuralismo, parece arrepentido al pasar al examen de la obra de Edmund Leach. En efecto, lo primero que advierte Krader al inicio de este subtítulo, es que "no podemos estar de acuerdo con el sistema del estructuralismo, ya sea de Lévi-Strauss o de E. R. Leach... al igual que no podemos estarlo con el sistema de E. Cassirer del mito como una forma simbólica, ni con el sistema de Carl Jung de los símbolos míticos" (p. 181). Krader comenta que, si bien Lévi-Strauss y Edmund Leach son ambos estructuralistas, difieren en puntos básicos y, principalmente, en su noción de cultura. La comparación entre LéviStrauss y Leach es un medio usado por Krader para llegar a establecer "Observaciones" (p. 183) generales resumidas en la afirmación de que no existe ninguna lógica particular en el mito o una forma de razonar asociada al mismo. La especulación que caracteriza al mito es la misma que caracteriza a cualquier discurso. El mito es un artificio de la comunicación humana. "En el mito, como en la especulación, defendemos con igual fuerza y con el mismo sentido de convicción interna el afirmativo y el negativo de una posición o principio para convencer a los demás" (p. 183). Según lo anterior, lo sustancial en el mito es no tener reglas ni una realidad primordial. Por lo 
mismo, el mito es excepcionalmente variable, tanto en contenido - su sustancia - como en la forma ("pro forma”, solía decir Krader en su latín castellanizado con el que nos hablaba).

Es decir, todo intento de entender el mito a partir de su forma o su contenido está condenado al fracaso. La discusión de este último aspecto lleva a Krader a revisar nuevamente a los estructuralistas ("El mito como código", p. 184; "Los códigos, el criptoanálisis y las claves", p. 188), comparando nuevamente a Lévi-Strauss y Leach. Debe leerse con extrema concentración esta parte del libro de Krader y tener en cuenta lo que escribió previamente en Dialectic of Civil Society (1976) y A Treatisse of Social Labor (1979).

Los problemas que Krader señala

198 a lo largo de su compleja discusión de los estructuralistas no serán resueltos sino hasta la sección final del libro titulada "Forma y sustancia del mito" (p. 201). Aquí se le aclara al lector que la opinión de Krader es que no existe una forma general del mito: los mitos son especificos tanto en su forma como en su contenido, porque son producidos por sociedades concretas en momentos históricos determinados. Para demostrarlo, Krader discute el aspecto de la redundancia en el mito (p. 203), la forma y la sustancia en el mito (p. 212), el mito esotérico y el mito exotérico (p. 214), para llegar al planteamiento del mito del Estado (p. 221), regresando a la discusión comparada de Hobbes y Hegel.

La experiencia de Krader con la sociedad de los mongoles en particular y su conocimiento de Asia en general, se expresan en esta parte de la obra. La erudición sigue esgrimiéndose con gran eficacia por parte de Krader. En "Mito sagrado y mito secular" (p. 231), se discuten extensamente las nociones de lo sagrado y lo secular, invocándose a etnólogos, filósofos, sociólogos o historiadores. En el subtítulo "Lo absurdo y lo irracional" se continúa la discusión pero ahora mostrándose los usos narrativos y plásticos del mito. Es decir, los mitos son figurativos y prosopográficos, $y$ así se introducen al sentimiento religioso y al pensamiento y la reflexión en general (p. 244).

En el subtítulo "Lo absurdo y lo irracional”, Krader introduce un elemento que no aparece antes en su argumentación: el mito como mentira. Lo hace para acercarnos al examen de la ideología. Para quienes se interesan en la discusión de lo simbólico, encontrarán aquí un tratamiento complejo del mito como representación colectiva.

En el siguiente subtítulo, "Los mitos de la utopía, la técnica y la máquina”, Krader discute cómo el mito se ha divorciado de su tradición y de lo sobrenatural, sin romper sus vínculos con lo sagrado y con las tradiciones del pasado. Así mismo, el ritual ha sido también secularizado en los aspectos jurídicos y políticos en general. Existen mitos políticos. Incluso, hay dogmas políticos que se vuelven sagrados, así como existen iglesias o asociaciones religiosas que son, a su vez, instituciones políticas. El examen del mito político lleva a Krader a la conclusión de que los mitos son emocionales e intelectuales en su forma y en su contenido. Krader discute en extenso la noción de utopía, tan cara al antropólogo mexicano Esteban Krotz (véase su libro Utopía, México, UAM-Iztapalapa, 1988).

En el subtítulo "Los mitos de la ciencia: el cocodrilo de Kapitza” (p. 253), Krader escribe: "Un mito que prevalece en nuestro tiempo es el de la ciencia” (p. 253). El propósito de Krader es demostrar que no existe neutralidad en el uso de la ciencia y por ello trae a colación a Kapitza, un periodista que comparó el camino del cocodrilo con la trayectoria de la ciencia: ninguno se desvía, ni a la izquierda ni a la derecha. Pero Krader advierte que la ciencia tiene usos políticos y que es un mito creer en su neutralidad. Esta discusión la relaciona Krader con un tema que ha sido recurrente en él: "Friedrich Engels y el mito de la dialéctica de la naturaleza" (p. 234), bajo cuyo subtítulo se contiene la crítica al materialismo dialéctico. Quienes están familiarizados con la obra de Krader recordarán, al leer esta parte del libro, su Dialectic of Civil Society (1976) y sus ensayos, "The Works of Marx and Engels en Ethnology Compared", publicados desde 1973 y hasta 1976 en la Internacional Review of Social History.

Krader plantea que la idea de que la naturaleza es dialéctica es un mito. La dialéctica es una propiedad de la historia y ésta la hacen los seres humanos. Por lo tanto, suponerle a la naturaleza una conciencia no pasa de ser un mito, así sea Engels el autor de tal propuesta. Los subtítulos que siguen, "Hertz y Nagel sobre los mitos de la ciencia" y "Mitos de los 
infinitesimales en la matemática" son la culminación de la discusión de Krader sobre el mito de la ciencia.

En "El mito en proceso de formación” (p. 261), el autor regresa al examen de Thomas Hobbes y de Hegel, proponiendo que las relaciones de los mitos del Estado, la ciencia y la tecnología se comprenderán mejor si se les considera como procesos en formación. Es decir, la mitificación del Estado, la ciencia y la tecnología tiene influencia en las visiones utópicas y en las escatológicas. A continuación de esta discusión, Krader compara las obras de Benedetto Croce, Barrington Moore Jr. y Karl Popper. Siguen una serie de subtítulos, "El mito como actividad y pasatiempo" "El mito como expresión ecuménica”, "El mito: lo conocido y lo desconocido" "El mito de Teseas y de Skiros", "La riqueza del mito", antes de llegar a la parte final subtitulada "Mito e ideología". En los subtítulos mencionados Krader afina su discusión preparando la parte final del libro. Se compone esta última, además de "Mito e ideología", del subtítulo "La ideología como activación del mito". En esta parte final, Krader expone su concepción de la ideología. Esta es una expresión social, negativa o positiva, "con la cual representamos, a los de afuera y a nosotros mismos, aquello de lo que huimos u odiamos o aquello que buscamos y deseamos" (p. 286). En las sociedades igualitarias basadas en el parentesco, la ideología se confunde con los mitos. Pero en las sociedades complejas, de economía política, con Estado y división en clases sociales, la ideología es expresión del propio Estado o de los partidos políticos. El mito y la ideología tienen una historia que va desde su mezcla hasta su separación. Los mitos y las ideologías - dice Krader- no expresan ni representan la realidad social, pero esta puede dilucidarse en los contenidos mitológicos e ideológicos.

Mito e ideología es un libro complejo. Sin duda, provocador de una dis- cusión que tiene varios matices y facetas. Con esta obra, Lawrence Krader selló una producción bibliográfica que aún no ha sido valorada por los antropólogos como se debe. Él mismo solía decir en la década de 1970 que su trabajo "es para el siglo XXI". Con oportunidad entonces, nos llega esta obra en donde Krader se nos muestra como el gran antropólogo que fue, moviéndose en los parámetros del análisis cultural con una gran erudición. No deja de ser una señal de los tiempos el que el libro se publique primero en castellano y en México, país donde Krader se sintió bien y donde su obra ha tenido seguidores de la importancia de Brígida Von Mentz o Mayan Cervantes.

Las excelentes y eruditas "notas complementarias" de Alberto Cue enriquecen notablemente esta edición.

logía. La consulta de sus notas es parte obligada de la lectura del libro de Krader. 